\title{
Argentina y el FMI: un enfoque histórico de las condicionalidades y su incidencia en los derechos humanos económicos y sociales, 1956-2020
}

\author{
Argentina and the IMF: A bistorical approach \\ to conditionalities and their impact on economic \\ and social buman rights, 1956-2020
}

\section{Noemí Brenta ${ }^{1}$ UBA/CONICET, Argentina}

Revista Derechos en Acción ISSN 2525-1678/ e-ISSN 2525-1686

Año 6/No 18 Verano 2020-2021 (21 diciembre a 20 marzo), 311-345

DOI: https://doi.org/10.24215/25251678e484

Resumen: En primer lugar, este trabajo se refiere a los programas de Argentina con el FMI entre 1956 y 2020; luego se examinan las condicionalidades de los acuerdos stand by y de facilidades extendidas signados en el mismo período. Posteriormente, se analizan los efectos de los programas del FMI en la macroeconomía argentina a través de su impacto contractivo sobre el crecimiento, y el aumento de la inflación y del desempleo, variables que influyen directamente en el ejercicio de los derechos económicos y sociales; y se revela el deterioro de los indicadores sociales en una década completa bajo programas del organismo, la de la Convertibilidad y luego, nuevamente, en 2018-2019. Las conclusiones reflexionan sobre la influencia de las condicionalidades en

\footnotetext{
1 Investigadora y vicedirectora del Centro de Investigaciones en Historia Económica, Social y de las Relaciones Internacionales, del Instituto de Estudios Históricos, Económicos, Sociales e Internacionales, Unidad Ejecutora en Red del Conicet, Facultad de Ciencias Económicas, Universidad de Buenos Aires (FCE UBA). Investigadora y docente de la Universidad Tecnológica Nacional, Facultad Regional Gral. Pacheco y de la FCE UBA. La autora agradece la colaboración de Hannah de Meneses, becaria del Programa de Pasantías de Investigación de la Facultad de Ciencias Económicas de la Universidad de Buenos Aires.
} 
la configuración económica argentina y sobre la discrecionalidad del FMI en la aprobación del stand by y su ampliación en 2018.

\begin{abstract}
This paper refers to IMF's programs with Argentina between 1956 and 2020. The conditionalities of the stand-by and extended facilities agreements signed during the same period are examined. Subsequently, the effects of IMF programs on the Argentine macroeconomy are analyzed through their contractionary impact on growth, and the increase in inflation and unemployment, variables that directly influence the exercise of economic and social rights. The deterioration of social indicators in a full decade under IMF programs, during Convertibility regime, and again in 2018-2019 is revealed. The conclusions reflect on the influence of conditionalities in the Argentine economic configuration and on the IMF's discretionality in the approval of the stand-by agreement and its extension in 2018.
\end{abstract}

\title{
1. Introducción
}

Argentina es un cliente especial del FMI. Por un lado, es el país de ingresos medios que ha permanecido más tiempo bajo programas del organismo; ellos marcaron profundamente la economía y la sociedad del país, a través de sus exigencias de políticas de coyuntura y de reformas estructurales. Además, Argentina es el miembro del FMI que recibió el mayor stand by de la historia del organismo, ${ }^{2}$ en junio de 2018, desembolsado en un $80 \%$ en solo trece meses, gracias a la influencia del presidente estadounidense Donald Trump, con el objetivo explícito ${ }^{3}$

2 El 20 de junio de 2018 el Directorio Ejecutivo del FMI aprobó un stand by para Argentina por 35379 millones de degs, equivalentes a 50000 millones de dólares, aumentado a 40.714 millones de DEGS (56 300 millones de dólares) el 26 de octubre de 2018 (IMF, "IMF Executive Board Completes First Review Under Argentina's Stand-Arrangement, Approves US\$5.7 Billion Disbursement", Press Release Núm. 18/395, 26 de octubre de 2018, disponible en https:// www.imf.org/ /media/Files/Publications/CR/2018/cr18297-ArgentinaBundle.ashx).

3 Mauricio Claver Carone, "Estados Unidos en el contexto hemisférico", videoconferencia en el Consejo Chileno para las Relaciones Internacionales, 22-7-20, YouTube (https://bit.ly/32TtjMn). 
de sostener al gobierno que reinstauró el neoliberalismo en beneficio del gran capital.

En los períodos bajo acuerdos con el organismo la economía argentina acumula recesión, mayor inflación, desempleo, pobreza y regresividad distributiva, que la permanencia bajo programas del organismo dificulta revertir. Estos también fueron los resultados del stand by aprobado en 2018, suspendido en 2020 por el gobierno argentino, cuyo repago se encuentra en forzada renegociación al momento de elaborar este artículo, ya que el cronograma de reembolso planteado inicialmente era imposible de cumplir, lo que garantizaba nuevamente un largo período bajo programas del organismo, para profundizar el rediseño neoliberal de la economía argentina.

El Directorio del FMI aprobó y amplió este stand by, a pesar de que las condiciones para otorgar el acceso extraordinario a los recursos no se cumplían, como se mostrará más adelante; y también aprobó cuatro revisiones que liberaron sendos desembolsos, aunque esos fondos se destinaron principalmente a financiar la salida de capitales, ${ }^{4}$ destino prohibido en el art. VI, Sección 1, a) del Convenio Constitutivo del organismo y su normativa complementaria.

En primer lugar, este trabajo se refiere a los programas de Argentina con el FMI entre 1956 y 2020; luego se examinan las condicionalidades de los acuerdos stand by y de facilidades extendidas signados en el mismo período. Posteriormente, se analizan los efectos de los programas del FMI en la macroeconomía argentina a través de su impacto contractivo sobre el crecimiento, y el aumento de la inflación y del desempleo, variables que influyen directamente en el ejercicio de los derechos económicos y sociales; y se revela el deterioro de los

\footnotetext{
4 Para un análisis de la fuga de capitales en Argentina y su relación con el FMI, ver BCRA, Mercado de cambios, deuda y formación de activos externos, 2015-2019, Buenos Aires, 2020. Disponible en http://www.bcra.gov.ar/Pdfs/PublicacionesEstadisticas/Informe-Mercadocambios-deuda- \%20formacion-de-activos \%20externo- \%202015-2019.pdf.
} 
indicadores sociales en una década completa bajo programas del organismo, la de la Convertibilidad, y nuevamente en 20182019. Las conclusiones reflexionan sobre la influencia de las condicionalidades en la configuración económica argentina y sobre la discrecionalidad del FMI en la aprobación del stand by y su ampliación, en 2018. Las conclusiones reflexionan sobre la influencia de las condicionalidades en la configuración económica argentina y sobre la discrecionalidad del FMI en la aprobación del stand by y su ampliación, en 2018.

\section{Los programas de Argentina con el FMI}

Entre 1956 y 2020, el directorio del FMI aprobó 21 acuerdos stand by y dos de facilidades extendidas solicitados por Argentina, además de otros tipos de financiamiento, como el tramo reservas (antes tramo oro), el primer tramo de crédito, y las líneas vigentes en las décadas de 1970 y 1980 para financiar los déficits externos por el aumento de la factura petrolera y la caída de las exportaciones (cuadro 1). Esto significa que Argentina pasó mucho tiempo bajo programas del FMI, que gravitaron fuertemente en su configuración económica. ${ }^{5}$

Si se consideran solo los acuerdos de mayor condicionalidad — stand by y facilidades extendidas-, 38 de los 50 años corridos entre 1956 y 2006, es decir, desde el ingreso del país al organismo hasta la cancelación total de su deuda con él, transcurrieron bajo programas del FMI. Luego, durante doce años, Argentina no tuvo ningún tipo de acuerdo, aunque conservó su membresía. Pero en 2018, tras desmantelar todos los mecanismos de precaución del balance de pagos y de provocar graves desequilibrios del sector externo, el gobierno neoliberal obtuvo del FMI un stand by de monto inusitado, equivalente a

5 Para un análisis de la influencia de los programas del FMI en la economía argentina entre 1956 y 2006, ver Noemí Brenta, Historia de las relaciones entre Argentina y el FMI, (Eudeba, Buenos Aires, 2013). 
12,77 veces la cuota argentina, cuando el máximo posible según la normativa del organismo era 4,35 veces.

Es necesario mencionar que antes de 2018, la deuda con el FMI siempre representó un porcentaje menor del financiamiento externo total de la Argentina, su rol tradicional fue más bien el de facilitar otros préstamos. La reducida capacidad financiera del FMI y los montos usualmente limitados - de tres a cinco veces la cuota del país miembro, salvo circunstancias excepcionales- explican este rasgo. De hecho, la deuda argentina con el FMI promedió entre $4 \%$ y $5 \%$ de la deuda externa pública entre 1956 y 2005, con picos de $7 \%$ a $9 \%$ en los años 2000 a 2002 y 1956 a $1959 .{ }^{6}$ Y, excepto en las dos ampliaciones de 2001 del stand by entonces vigente, todos los acuerdos se mantuvieron dentro de los límites prefijados. Actualmente los 44500 millones de dólares que Argentina adeuda al FMI representa el $26 \%$ de la deuda externa pública, y preanuncia muchos años de sujeción a las condicionalidades de sus programas, a menos que el país encuentre un modo de cancelarla que la libere de esta carga indeseable.

La discrecionalidad de las decisiones en el FMI se refleja en el monto acordado a Argentina en 2018 y en el cronograma de pagos, de cumplimiento imposible. Forzando los datos, los funcionarios del FMI consideraron que Argentina cumplía los cuatro criterios requeridos para acordarle el acceso excepcional a los recursos del organismo. En primer lugar, las necesidades de balance de pagos (dólares) de Argentina excedían los límites normales de acceso a los recursos del FMI; además — dijeron-, aunque su deuda era "sostenible pero no con alta probabilidad", tenía fuentes de financiamiento adicionales al FMI, como el swap con China y un acceso limitado a los mercados. El tercer criterio establecía que el miembro tendría suficiente acceso a los mercados de capital privados en una escala tal que le permitiría cumplir sus deudas con el FMI; una arriesgada proyección

6 Brenta, op. cit. (nota 5), 307. 
a futuro. Por último, el staff estimaba que el programa económico era viable, y que el ajuste podía implementarse y gestionarse institucional y políticamente. De estos cuatro criterios, solo el primero era contundente. El segundo suponía que la deuda pública permanecería bajo el umbral del $70 \%$ del PIB, pero a pocos días de la aprobación del stand by basado en este supuesto, entre otros, las cifras oficiales lo desmintieron, la deuda de la administración central ya alcanzaba al 77,4\% del PIB a fin de junio de 2018, los técnicos del FMI no podían ignorarlo. Aun así, justificaron el acceso excepcional bajo este criterio porque el país todavía podía tomar deuda en los mercados, y, a su juicio, eso le facilitaría suavizar el ajuste, crecer y lograr consenso político y social para sostener el programa comprometido. En esto tampoco acertaron, el ajuste contrajo la producción y aumentó el desempleo, la pobreza, el riesgo país y el descrédito gubernamental. Las consideraciones para aprobar los criterios tercero y cuarto eran puramente ideológicas e ilusorias, suponían que profundizar las políticas ortodoxas que llevaron a la crisis en Argentina y otros países esta vez podrían resultar diferentes, y apoyaban con nombre y apellido al gobierno que llevó a un nuevo sobreendeudamiento externo, con el FMI como el mayor acreedor individual.

Cuadro 1. Argentina. 1956-2020. Autorizaciones de giro y acuerdos con el FMI

\begin{tabular}{|c|c|c|c|c|c|}
\hline \multirow{2}{*}{$\begin{array}{l}\text { Fecha de } \\
\text { aprobación }\end{array}$} & \multirow{2}{*}{$\begin{array}{l}\text { Tipo de acuerdo o de } \\
\text { autorización de giro }\end{array}$} & \multicolumn{2}{|c|}{$\begin{array}{l}\text { * Montos, en } \\
\text { millones }\end{array}$} & \multicolumn{2}{|c|}{$\begin{array}{c}\text { Montos, } \% \text { de la } \\
\text { cuota }\end{array}$} \\
\hline & & Acordado & Girado & Acordado & Girado \\
\hline 17-abr-57 & $\begin{array}{l}\text { Tramo oro y primer tramo de } \\
\text { crédito }\end{array}$ & 75 & 75 & 50 & 50 \\
\hline 4-dic-58 & Stand by & 75 & 43 & 50 & 28 \\
\hline 24-nov-59 & Stand by & 100 & 100 & 36 & 36 \\
\hline 9-dic-60 & Stand by & 100 & 60 & 36 & 21 \\
\hline 22-nov-61 & Stand by & 100 & 0 & 36 & 0 \\
\hline 6-jun-62 & Stand by & 100 & 100 & 36 & 36 \\
\hline
\end{tabular}




\begin{tabular}{|c|c|c|c|c|c|}
\hline \multirow{2}{*}{$\begin{array}{l}\text { Fecha de } \\
\text { aprobación }\end{array}$} & \multirow{2}{*}{$\begin{array}{l}\text { Tipo de acuerdo o de } \\
\text { autorización de giro }\end{array}$} & \multicolumn{2}{|c|}{$\begin{array}{l}\text { * Montos, en } \\
\text { millones }\end{array}$} & \multicolumn{2}{|c|}{$\begin{array}{c}\text { Montos, } \% \text { de la } \\
\text { cuota }\end{array}$} \\
\hline & & Acordado & Girado & Acordado & Girado \\
\hline 18-mar-63 & $\begin{array}{l}\text { Stand by, extensión del acuerdo } \\
1962\end{array}$ & 50 & & 18 & 0 \\
\hline 28-ene-66 & Segundo tramo de crédito & 30 & 30 & 9 & 9 \\
\hline 10-ago-66 & $\begin{array}{l}\text { Compra para pagar aumento de } \\
\text { cuota }\end{array}$ & 18 & 18 & 5 & 5 \\
\hline 1-may-67 & Stand by & 125 & 0 & 36 & 0 \\
\hline $15-a b r-68$ & Stand by & 125 & 0 & 36 & 0 \\
\hline 1-mar-72 & $\begin{array}{l}\text { Compensatorio por } \\
\text { fluctuaciones de exportaciones }\end{array}$ & 326 & 64 & 74 & 15 \\
\hline 9-mar-72 & Tramo oro & 110 & 110 & 25 & 25 \\
\hline 14-jun-72 & Primer tramo de crédito & 110 & 110 & 25 & 25 \\
\hline 17-jun-75 & Tramo oro & 110 & 110 & 25 & 25 \\
\hline 20-oct-75 & Servicio financiero del petróleo & 76 & 76 & 17 & 17 \\
\hline 23-dic-75 & $\begin{array}{l}\text { Compensatorio por } \\
\text { fluctuaciones de exportaciones }\end{array}$ & 110 & 110 & 25 & 25 \\
\hline 18-mar-76 & $\begin{array}{l}\text { Compensatorio por } \\
\text { fluctuaciones de exportaciones }\end{array}$ & 110 & 110 & 25 & 25 \\
\hline 6-ago-76 & $\begin{array}{l}\text { Primer tramo de crédito } \\
\text { ampliado y stand by }\end{array}$ & 260 & 160 & 59 & 36 \\
\hline 16-sep-77 & Stand by & 160 & 0 & 36 & 0 \\
\hline $\begin{array}{l}22 \text { dic } 82 \text { y } \\
7 \text { ene } 83\end{array}$ & Tramo reserva & 201 & 201 & 37 & 37 \\
\hline 24-ene-83 & $\begin{array}{l}\text { Stand by y compensatorio por } \\
\text { fluctuaciones de exportaciones }\end{array}$ & 1500 & 601 & 187 & 75 \\
\hline 28-dic-84 & $\begin{array}{l}\text { Stand by y compensatorio por } \\
\text { fluctuaciones de exportaciones }\end{array}$ & 275 & 275 & 25 & 25 \\
\hline 23-feb-87 & $\begin{array}{l}\text { Compensatorio por } \\
\text { fluctuaciones de exportaciones }\end{array}$ & 389 & 389 & 35 & 35 \\
\hline 23-jul-87 & Stand by & 1113 & 804 & 100 & 72 \\
\hline 26 -feb-88 & $\begin{array}{l}\text { Compensatorio por } \\
\text { fluctuaciones de exportaciones }\end{array}$ & 233 & 233 & 21 & 21 \\
\hline 10-nov-89 & Stand by & 1104 & 506 & 99 & 45 \\
\hline
\end{tabular}




\begin{tabular}{|c|c|c|c|c|c|}
\hline \multirow{2}{*}{$\begin{array}{l}\text { Fecha de } \\
\text { aprobación }\end{array}$} & \multirow{2}{*}{$\begin{array}{l}\text { Tipo de acuerdo o de } \\
\text { autorización de giro }\end{array}$} & \multicolumn{2}{|c|}{$\begin{array}{l}\text { * Montos, en } \\
\text { millones }\end{array}$} & \multicolumn{2}{|c|}{$\begin{array}{l}\text { Montos, } \% \text { de la } \\
\text { cuota }\end{array}$} \\
\hline & & Acordado & Girado & Acordado & Girado \\
\hline 29-jul-91 & Stand by & 780 & 439 & 70 & 39 \\
\hline \multirow[t]{3}{*}{ 31-mar-92 } & $\begin{array}{l}\text { Facilidades extendidas, luego } \\
\text { aumentado y prorrogado: }\end{array}$ & 4020 & 4020 & 361 & 361 \\
\hline & 31-mar-92 & 2483 & & 223 & - \\
\hline & $6-a b r-95$ & 1537 & & 100 & - \\
\hline 12-abr-96 & Stand by & 720 & 613 & 47 & 40 \\
\hline 4-feb-98 & Facilidades extendidas & 2080 & 0 & 98 & 0 \\
\hline \multirow[t]{4}{*}{ 10-mar-00 } & Stand by, luego aumentado & 16937 & 9757 & 800 & 461 \\
\hline & 10-mar-00 & 5399 & & 255 & \\
\hline & 12-ene-01 & 5187 & & 245 & \\
\hline & 21-ago-01 & 6351 & & 300 & \\
\hline 24-ene-03 & Stand by & 2175 & 2175 & 103 & 103 \\
\hline 20-sep-03 & Stand by & 8981 & 4171 & 424 & 197 \\
\hline \multirow[t]{3}{*}{ 20-jun-18 } & Stand by, luego aumentado & 40714 & 31914 & 1277 & 1001 \\
\hline & monto original 20/06/2018 & 35379 & & 1110 & \\
\hline & aumento 26/10/2018 & 5335 & & 167 & - \\
\hline
\end{tabular}

* En dólares hasta 1970; en DEGs desde 1971

Fuente: Elaboración propia con datos del FMI, Informe Anual y acuerdos de Argentina con el FMI.

\subsection{La posición del FMI durante la dictadura cívico-militar de 1976-1983}

Especial mención requiere en este número especial sobre el FMI y los derechos humanos, el trato favorable que el organismo brindó a la dictadura más sangrienta que asoló a la Argentina entre 1976 y 1983, y que contrajo la gran deuda externa que postró al país durante varias décadas, y la mantuvo permanentemente bajo programas del FMI, sujeta a sus condicionalidades.

Tres memorándums confidenciales de los archivos del FMI revelan que sus funcionarios sabían que se avecinaba un golpe 
de estado, ${ }^{7}$ dilataron los tiempos de las negociaciones a la espera de que se produjera ${ }^{8}$, denegaron al gobierno constitucional el desembolso del último tramo de las facilidades petroleras —véase en el cuadro 1 que de los 76 millones de dólares acordados en 1975 solo se desembolsaron 17-; y si bien el 18 de marzo de 1976 se autorizó el acceso al financiamiento compensatorio de exportaciones, ${ }^{9}$ su desembolso de 110 millones de dólares se demoró hasta el 26 de marzo de 1976, dos días después del golpe. En mayo de 1976 una misión del FMI viajó a Buenos Aires para elaborar el informe del artículo VIII y comenzar a negociar el próximo acuerdo. El jefe de la misión, Jack Guenther, consideraba que el plan de Martínez de Hoz tenía grandes probabilidades de éxito, porque el abrupto cambio de la política de ingresos ya había disminuído el salario real un 20 \% y la inflación empezaba a ceder. ${ }^{10}$ Esto último fue muy efímero, porque muy pronto la inflación nuevamente se aceleró, sumó 444 \% en 1976, y de hecho durante todos años de la dictadura la inflación fue de tres dígitos, aun así, el directorio ejecutivo del FMI aprobó dos stand by solicitados por la dictadura en años consecutivos.

El primero, en agosto de 1976 por 300 millones de dólares, fue el mayor acordado a un país latinoamericano hasta entonces. El segundo, aprobado en septiembre de 1977 fue innecesario, ya que el país no padecía dificultades de balance de pagos, tenía reservas internacionales adecuadas y estaban ingresando capitales por la reforma financiera y el endeudamiento externo. De ese acuerdo no se retiró un solo dólar, solo actuó como respaldo del

\footnotetext{
7 IMF, Office Memorandum de Jorge del Canto, director del Departamento del Hemisferio Occidental (América Latina) al director gerente y subdirector gerente, Washington, 3 de febrero de 1976.

8 IMF, Memorándum de Jack D. Guenther, jefe de la misión del FMI realizada a la Argentina, al director gerente, 21 de febrero de 1976. Cabe destacar el siguiente párrafo: "Los militares, mientras tanto, están permitiendo que la situación se continúe deteriorando, sin embargo, hay rumores diarios de que actuarán pronto".

9 IMF, Memorándum de Jorge del Canto al director gerente, (10 de marzo de 1976).

10 IMF, Memorándum de Jack Guenther al director gerente, (15 de junio de 1976).
} 
devastador programa económico implementado. De modo similar al stand by de 2018, el gobierno de Estados Unidos brindó un apoyo decisivo para su aprobación. El directorio ejecutivo lo aprobó a instancias del representante estadounidense, pese a la oposición de seis directores europeos, que objetaban que en la solicitud de la Argentina faltaba la meta antiinflacionaria, omisión importante, ya que el país tenía entonces una de las tasas de inflación más elevadas del mundo. Sam Cross impuso su punto de vista, que era el del Tesoro estadounidense, y presionó para la aprobación del préstamo, diciendo que le "agradaba el considerable y continuado progreso que había logrado la economía argentina con la oportuna ayuda proporcionada por el FMI". ${ }^{11}$

La dictadura no solicitó otros acuerdos al FMI hasta la crisis de la deuda de 1982, en razón de las sanciones por las graves violaciones a los derechos humanos, impuestas por la administración Carter (1977-1980), no sin ambigüedad y disputa entre distintas agencias del gobierno federal. En síntesis muy apretada, en octubre de 1976, Kissinger, secretario de Estado norteamericano aconsejó a la dictadura apurar la matanza de opositores antes de la reanudación de las sesiones del congreso, ${ }^{12}$ y también advirtió a al ministro de relaciones exteriores argentino que Estados Unidos por el momento se abstendría en la votación de préstamos en los bancos multilaterales, en los términos de la enmienda Harkin, pero que este voto pasaría a ser negativo, si la junta no mejoraba la situación de los derechos humanos en Argentina. ${ }^{13}$ La enmienda Harkin,

11 Botzman, Lifschitz y Renzi, 1979, citado por Jorge Schvarzer, Martínez de Hoz: la lógica política de la política económica, CISEA, (Buenos Aires, 1983), 57.

12 Departamento de Estado, Memorándum de conversación del 7 de octubre de 1976, entre Henry Kissinger, secretario de estado norteamericano; y los argentinos César A. Guzzetti; Arnaldo T. Musich, embajador en los Estados Unidos; y Carlos Ortiz de Rosas, embajador en las Naciones Unidas.

13 Minuta de la reunión entre Kissinger y Guzetti, documento desclasificado, (20 de octubre de 1976). 
aprobada en 1975, prohibía al gobierno estadounidense brindar ayuda alimentaria a países cuyos gobiernos violaran los derechos humanos básicos. En 1976, esta prohibición se extendió a los votos estadounidenses en el Banco Interamericano de Desarrollo y en el Fondo Africano de Desarrollo, y en octubre de 1977, a todas las instituciones financieras internacionales, incluyendo el FMI y el Banco Mundial. Las sanciones fueron más simbólicas que efectivas: Argentina accedió a la mayoría de los préstamos a los que se opuso el representante estadounidense, gracias a los votos positivos de los demás países. Pero contribuyeron a salvar algunas vidas, a difundir el tema internacionalmente, y a cuestionar la pretensión de impunidad del gobierno de facto. ${ }^{14}$

\section{Las condicionalidades de los programas del FMI en Argentina}

Según el discurso institucional del FMI, sus condicionalidades buscan asegurar el repago de sus "préstamos"15 y corregir los desequilibrios del sector externo que llevaron a un país miembro a recurrir al organismo. Pero, en los hechos, las condicionalidades contribuyeron a profundizar la inestabilidad de la economía argentina y favorecieron los intereses estratégicos de Estados Unidos y de los países avanzados con influencia global, y al gran capital transnacional, industrial y financiero.

Todos los programas del FMI en Argentina agravaron la debilidad del balance de pagos, luego de habilitar un breve lapso de ingreso de capitales que aumentaron la deuda externa sin la contrapartida de mejorar la capacidad de atenderla; y tras obligar a una mayor apertura importadora, con su consecuente déficit comercial, en un contexto de apreciación de la

\footnotetext{
14 Para un tratamiento más detallado de este tema, ver Brenta, op. cit. (nota 5), 107-112.

15 El uso de recursos del FMI por parte de los países miembros no consiste en préstamos sino en compra de moneda internacional con moneda doméstica, mecanismo similar a un swap de monedas. Los préstamos se implementaron desde la década de 1970 y solo se destinan a los países muy pobres.
} 
moneda doméstica, además de deteriorar otros rubros de la cuenta corriente. Es decir que el propósito de restaurar el equilibrio externo enunciado en los programas del FMI es meramente retórico. Usualmente el equilibrio externo bajo programas del FMI se obtiene en el corto plazo, por la caída de las importaciones a causa de la recesión inducida por el ajuste y su encarecimiento causado por la devaluación, pero rápidamente el déficit de la cuenta corriente reaparece, a causa de la propia dinámica involucrada en los programas del FMI. Todos los períodos de vigencia de acuerdos con el FMI, bajo la vigilancia estrecha del organismo, finalizaron en Argentina con una crisis del sector externo. La reiteración de programas del FMI agudizó la inestabilidad estructural de la restricción externa, característica de esta economía periférica.

Desde su ingreso al organismo, Argentina revistó entre los países que debían cumplir mayor número de condicionalidades. Horsefield, ${ }^{16}$ el historiador oficial del FMI que reseñó el período 1945-1965, señalaba el trato discriminatorio del FMI hacia sus países miembros. Mientras que en aquellos años, el Reino Unido y Sudáfrica estaban exentos de condicionalidades, Francia y unos pocos solo debían comprometer una o dos condiciones, y el resto al menos siete. Stubbs y Kentikelenis ${ }^{17}$ señalan, en su artículo reproducido en este mismo número de REDEA, que Argentina fue uno de los países sometidos a la mayor cantidad de condicionalidades en los stand by de la década de 1980.

Las condicionalidades incluyen las medidas que el FMI considera esenciales o que acepta considerar esenciales, a pedido de las autoridades del país miembro. Su incumplimiento puede

\footnotetext{
16 Keith Horsefield, The International Monetary Fund 1945-1965. Twenty years of International Monetary Cooperation, IMF, (Washington, 1969), 432.

17 Thomas Stubbs y Alexander Kentikelenis, "Conditionality and Sovereign Debt. An Overview of Human Rights Implications", en Illias Bantekas y Cephas Lumina (ed.), Sovereign Debt and Human Rights, (Oxford University Press), Oxford, 2018, 359-380.
} 
provocar la suspensión de un acuerdo o de los desembolsos dentro de un acuerdo, o la negociación de una dispensa o waiver, que son medidas correctivas o compensatorias del incumplimiento. Argentina ha implementado tres tipos de condicionalidades: las acciones previas que el FMI exige como requisito para aprobar un acuerdo de financiamiento o un desembolso; los criterios de ejecución cuantificables y sus proxies, las metas indicativas y las cláusulas de consulta; y las reformas estructurales. Estas últimas se introdujeron desde la década de 1980, para obligar a los países sujetos por grandes deudas a adoptar configuraciones amistosas con los mercados, acorde a la nueva etapa neoliberal. A partir de 2009 el FMI modificó el modo de diseñar y evaluar las reformas estructurales, para incluir a los países en crisis de la eurozona. Existen también otras condicionalidades, no enunciadas como tales, que forman parte de los compromisos de un país frente al FMI, y son evaluadas en forma general en las revisiones y al examinar la consistencia de los programas económicos ligados a los acuerdos con el organismo.

Revisar las condicionalidades obligatorias de los acuerdos entre Argentina y el FMI, en su mayoría cumplidos aceptablemente, revela los aspectos de la política económica argentina encuadrados en las recomendaciones del organismo. En primer término, se describen aquí las condicionalidades, y en un acápite posterior se analizan sus implicancias macroeconómicas que afectan los derechos humanos, sobre todo los derechos económicos y sociales.

El número de criterios de ejecución y de tipo estructural se incrementó a partir de la década de 1960, fue máximo en los años de crisis de la deuda desde 1983 hasta su regularización a través del Plan Brady en 1992, y luego del default soberano de 2001. El stand by de junio de 2018 conllevó un número muy elevado de condicionalidades, 18, incrementado a 22 en su ampliación en octubre del mismo año (cuadro 2). 
Cuadro 2. Argentina y FMI. Número de condicionalidades en acuerdos stand by y de facilidades extendidas. 1958-2018

\begin{tabular}{|c|c|c|c|}
\hline Año del acuerdo & $\begin{array}{c}\text { Criterios } \\
\text { de ejecución }\end{array}$ & $\begin{array}{c}\text { Criterios } \\
\text { estructurales* }\end{array}$ & Total \\
\hline 1958 & 2 & 2 & 4 \\
\hline 1959 & 2 & 0 & 2 \\
\hline 1960 & 1 & 0 & 1 \\
\hline 1961 & 1 & 0 & 1 \\
\hline 1962 & 2 & 0 & 2 \\
\hline 1963 & 3 & 1 & 4 \\
\hline 1967 & 7 & 3 & 10 \\
\hline 1968 & 5 & 4 & 9 \\
\hline 1976 & 4 & 2 & 6 \\
\hline 1977 & 3 & 2 & 5 \\
\hline 1983 & 6 & 11 & 17 \\
\hline 1985 & 7 & 12 & 19 \\
\hline 1987 & 7 & 9 & 16 \\
\hline 1989 & 7 & 2 & 9 \\
\hline 1991 & 7 & 1 & 8 \\
\hline 1992 & 6 & 4 & 10 \\
\hline 1996 & 4 & 0 & 4 \\
\hline 1998 & 5 & 0 & 5 \\
\hline 2000 & 6 & 0 & 6 \\
\hline ene-01 & 6 & 0 & 6 \\
\hline mar-01 & 6 & 0 & 6 \\
\hline sep-02 & 6 & 0 & 6 \\
\hline sep-03 & 11 & 8 & 19 \\
\hline jun-18 & 10 & 8 & 18 \\
\hline oct-18 & 10 & 12 & 22 \\
\hline
\end{tabular}

* Incluye bases de comparación estructural. Los Criterios de Desempeño Estructural (SPC) rigieron hasta 2009. Luego el seguimiento de la implementación de las reformas estructurales pasó a basarse en las revisiones.

Fuente: elaboración propia en base a los acuerdos entre Argentina y el FMI. 


\subsection{Criterios cuantitativos de ejecución}

Los criterios de ejecución, que cuantifican variables fácilmente mensurables, se concentran en tres áreas: fiscal, monetaria y deuda externa pública (Cuadro 3).

El modo de definir el déficit fiscal se volvió cada vez más exigente a lo largo de los años. El FMI exigía agrandar el espacio fiscal acorde al incremento de la deuda externa argentina, y el consiguiente aumento de los pagos de intereses y accesorios. En los acuerdos de 1967 a 1977, el déficit fiscal sumaba solo las necesidades de financiamiento de la administración central más las empresas públicas. En los años 1980 se incluyó el déficit cuasifiscal, del Banco Central; a fines de los noventa y hasta 2001, se amplió al déficit consolidado del gobierno nacional más las provincias y la Ciudad Autónoma de Buenos Aires.

En el acuerdo de 2003, el FMI ya no se conformó con la reducción del déficit fiscal, sino que exigió obtener superávit primario, esto es, un superávit antes del pago de intereses, asumiendo que el servicio de la deuda pública no se atendería con nueva deuda, a diferencia del criterio de los años anteriores, que llevó la emisión de bonos soberanos a niveles insostenibles para la capacidad de pago de Argentina. Cabe recordar que el déficit fiscal durante la convertibilidad (1991-2001) fue muy pequeño, y sus principales causas fueron tres. Por un lado, la pérdida de ingresos estatales por los aportes previsionales inducida por la reforma estructural que privatizó el régimen de jubilaciones y pensiones; por el otro, la caída de la recaudación tributaria por la larga recesión iniciada en 1998. Y el aumento de los servicios de la deuda explica el $63 \%$ del crecimiento del gasto público consolidado (nación más provincias) entre 1993 y 2001, mientras que los rubros del gasto primario redujeron su incidencia.

El stand by de junio de 2018 comprometió a reducir el déficit fiscal, definido como el del gobierno nacional (es decir, la administración central, las instituciones de seguridad social, los organismos descentralizados, PAMI y los fondos fiduciarios); y como meta indicativa, reducir el déficit primario del gobierno general 
(nación más provincias). En el stand by ampliado aprobado en octubre de 2018 los criterios se estrecharon, el gobierno se obligó a una reducción brusca del déficit primario del gobierno nacional, a eliminarlo totalmente en el año siguiente, 2019, y en los años sucesivos a obtener un superávit primario creciente. Ello se lograría, como es clásico, aumentando los impuestos y reduciendo el gasto, garantía de una segura recesión. Asimismo, el resultado fiscal primario del gobierno general (nación más provincias), ya no fue una meta indicativa sino un criterio de ejecución.

Dentro de los criterios de ejecución en el área fiscal, y acorde a la necesidad de legitimación del FMI y también del gobierno de Argentina frente a la resistencia social que despiertan los programas del organismo y al aumento del desempleo y la pobreza en 2017, el stand by de 2018 incluyó un piso del $0,2 \%$ del PIB en el gasto del gobierno nacional en programas de asistencia social. Ya en acuerdos stand by de Argentina con el FMI anteriores, principalmente el aprobado en 1984, el primer año de recuperación de la democracia, con Raúl Alfonsín en la presidencia y Bernardo Grinspun como ministro de economía, el gobierno logró insertar políticas sociales, pero no como condicionalidad, como en el caso de 2018.

En las cuestiones monetarias, ${ }^{18}$ todos los acuerdos, desde 1958 a 2003 y la ampliación de octubre de 2018, fijaron un techo a los activos domésticos del Banco Central, esto es, un límite a la creación de base monetaria por razones diferentes del aumento de las reservas internacionales. Los acuerdos que no prohibieron los préstamos del Banco Central al tesoro, acotaron la magnitud de la monetización del déficit fiscal (1962, 1963, 1967 y 1968).

Hasta 1996, los acuerdos estipularon un piso para las reservas internacionales, requisito que reapareció en 2003, agregándose en esta oportunidad un límite a la expansión de la base monetaria. La ausencia de piso a las reservas internacionales en

18 Sobre temas monetarios y cambiarios, y su efecto sobre los derechos humanos, ver el artículo de Alfredo Calcagno publicado en este mismo número de ReDeA. 
los acuerdos de Argentina y el FMI de 1998 y 2000, y la presión del director general del FMI sobre el ministro Cavallo, en agosto de 2001, para dolarizar la economía argentina si las reservas caían más de 2500 millones de dólares, sugiere que el FMI no deseaba cuantificar esta importante variable, porque necesitaba esta caída para cumplir el objetivo de sustituir el peso por el dólar estadounidense ${ }^{19}$.

Todos los acuerdos firmados sin cláusulas de limitación al endeudamiento externo público fueron seguidos de fuertes expansiones de la deuda soberana, que desembocaron en cuatro ocasiones en crisis de pagos internacionales: las de 1962, 1982, 2001 y 2018. La Argentina estuvo bajo acuerdos stand by con el FMI desde diciembre de 1958 hasta junio de 1963, pero éste nunca objetó el endeudamiento soberano hasta que la acumulación de vencimientos lo tornó insostenible en 1962. En 1967 y 1968, el gobierno de facto se comprometió con el FMI a financiar parcialmente el déficit con bonos la deuda externa pública, para ello emitió ocho empréstitos en los mercados internacionales hasta 1970. Pero en esta ocasión la crisis de pagos no se presentó, porque a pesar de la apreciación del peso, el saldo comercial se mantuvo discretamente positivo y el producto bruto creció más que la deuda externa, aunque la balanza de servicios acentuó su déficit por intereses pagados. También el gobierno de la Junta Militar suscribió dos acuerdos de giro en 1976 y 1977, sin límites para el endeudamiento externo, sextuplicándolo, hasta su retirada a fines de 1983. Ya finalizado el acuerdo con el FMI, éste continuó supervisando el proceso de endeudamiento a través de un experto contratado para determinar los montos de deuda que el gobierno argentino era capaz de absorber a través de las distintas agencias públicas, como se mencionó más arriba. Entre 1996 y 2000, bajo supervisión reforzada del FMI y acuerdos de condicionalidad fuerte sin cláusulas de límites al crecimiento de la deuda externa,

19 Ver Brenta, op. cit. (nota 5), 295-306. 
ésta creció un 38 \%, pasando de 90000 millones de dólares a 124000 millones a fines de 2001, cuando Argentina declaró su default soberano.

El stand by aprobado y ampliado en 2018 tampoco contuvo cláusulas de restricción al crecimiento de la deuda externa. Sendos criterios de ejecución en el acuerdo aprobado en junio estipulaban un techo a la acumulación de deuda flotante por pagos de deuda externa y deuda doméstica del gobierno nacional; y la ampliación de octubre fijó un límite a la acumulación de atrasos de los pagos de la deuda externa y doméstica. El informe del equipo técnico del FMI adjunto al stand by destacó el ritmo acelerado de la deuda externa pública, que pasó del 27,9 \% del PIB a fin de 2015 al $37 \%$ en 2017; saltó al 52,2 \% en 2018 —año del stand by-, y alcanzó el 59,8 \% del PIB al momento de la tercera revisión del acuerdo, en marzo de 2019. Estas cifras superaban largamente los umbrales de peligro que señala la guía para compilar la deuda externa, publicada por el FMI con otros organismos internacionales. ${ }^{20} \mathrm{Si}$ apenas el $20 \%$ de la deuda pública se denomina en moneda extranjera ya asoma un leve síntoma de riesgo ${ }^{21}$, si alcanza un $60 \%$ el peligro es considerable. En junio de 2018 el $75 \%$ de la deuda pública nacional, se denominaba en moneda extranjera, y el $81 \%$ si se incluyen las provincias. El análisis de sustentabilidad del FMI sobre la deuda decía que ella era sostenible pero no con alta probabilidad ("staff assesses debt to be sustainable but not with bigh probability") $)^{22}$.

Esto permite afirmar que la fijación de criterios cuantitativos en los acuerdos del FMI es operativa, fija cursos de acción, y

\footnotetext{
20 FMI, External Debt Statistics. Guide for compilers and users, (2014).

21 Debe recordarse que en Argentina no toda la deuda pública en moneda extranjera es deuda externa, definida esta última como la deuda en poder de no residentes. La ley de administración financiera 24156 establece que la deuda externa incluye la emitida bajo jurisdicción extranjera aun si sus tenedores residen en Argentina.

22 FMI, Argentina request for stand-by arrangement, Press Release and staff report, IMF Country Report No. 18/219, julio de 2018.
} 
se refleja en las decisiones de las autoridades que los solicitan y suscriben. Acuerdos celebrados sin cláusula de limitación al endeudamiento externo público fueron seguidos de fuertes expansiones de la deuda, que tarde o temprano desembocaron en crisis de pagos e intensificación del ajuste recesivo.

El enfoque teórico del FMI sobre el balance de pagos contempla el juego entre estas tres variables: resultado fiscal, agregados monetarios y deuda pública externa. Según este enfoque, para limitar la expansión de activos domésticos y evitar el desplazamiento del crédito al sector privado (crowding out), los déficits fiscales deben financiarse con deuda pública en los mercados de capitales internacionales. Pero los servicios de la deuda incrementan el gasto público, la recaudación tributaria cae debido a la recesión típicamente asociada a los programas del FMI, los ingresos públicos se reducen, y el déficit fiscal aumenta, obligando a tomar más deuda, etc. Pero el modelo fondomonetarista no considera estas relaciones funcionales. Sus proyecciones suponen que la deuda se refinanciará permanentemente, y asumen una tasa de crecimiento del producto bruto generalmente demasiado optimista. Estos sesgos son bien conocidos. De hecho, las proyecciones del FMI, hasta el default de 2001, asumían que la deuda se refinanciaría permanentemente y pronosticaban una tasa de crecimiento del producto bruto excesivamente optimista $(3,4 \%$ en 2000 y $-1,4 \%$ en 2001, que en la realidad fueron de $-0,5 \%$ y $-4,4 \%$ respectivamente), que subestimaba el riesgo de impago de la deuda soberana. De modo similar, las proyecciones del stand by de 2018 asumieron una caída del PIB en 2019 inferior a la efectivamente registrada $(-1,7 \%$ y $-2,2 \%$, respectivamente), y tasas positivas de crecimiento de 2020 a 2023. La pandemia del coronavirus en 2020 era impredecible, por cierto, el desplome de la actividad económica en todo el mundo, también en la Argentina, tornaron aun más irreales las proyecciones del FMI, y en incumplible todo criterio de ejecución. 


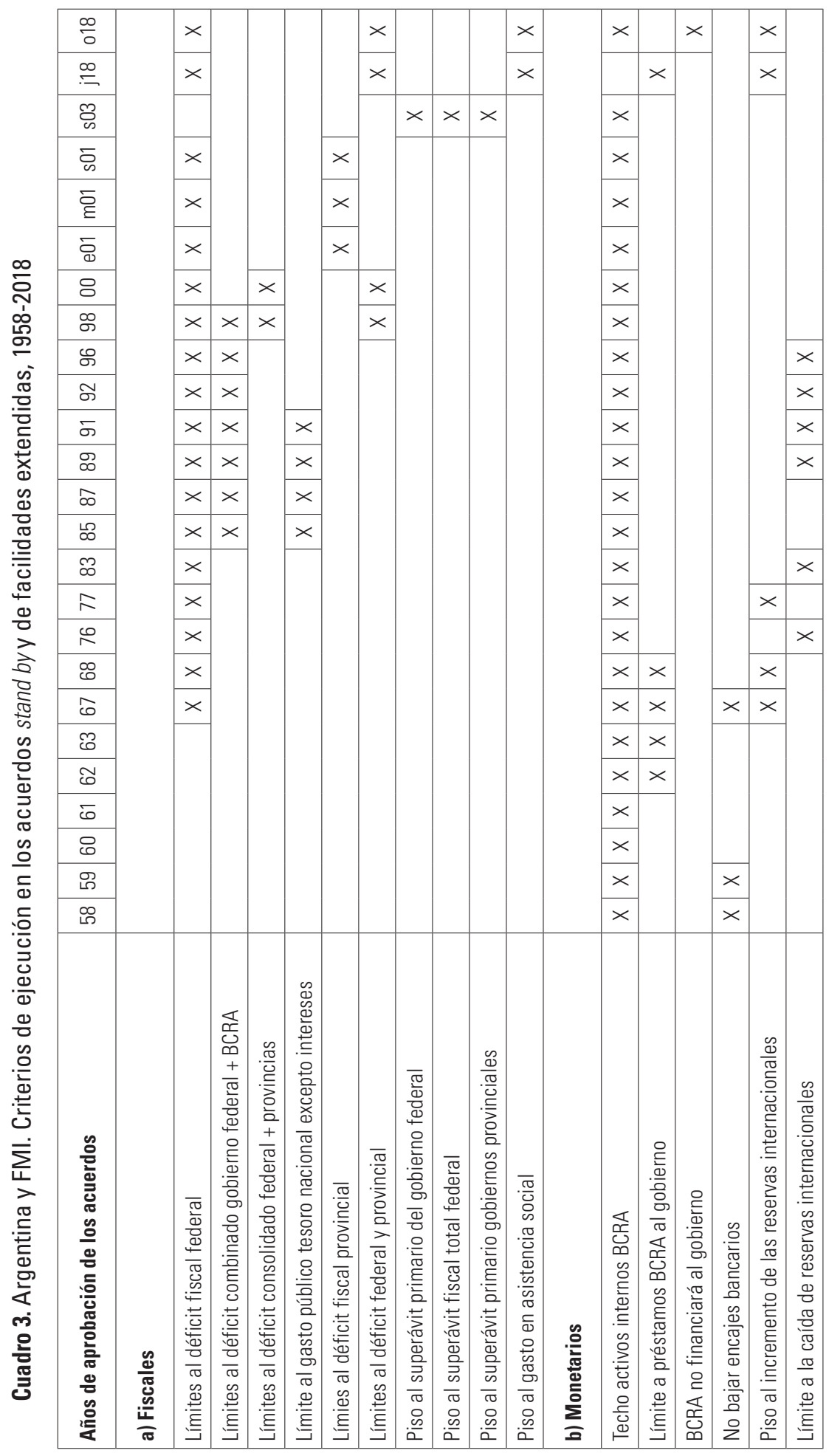




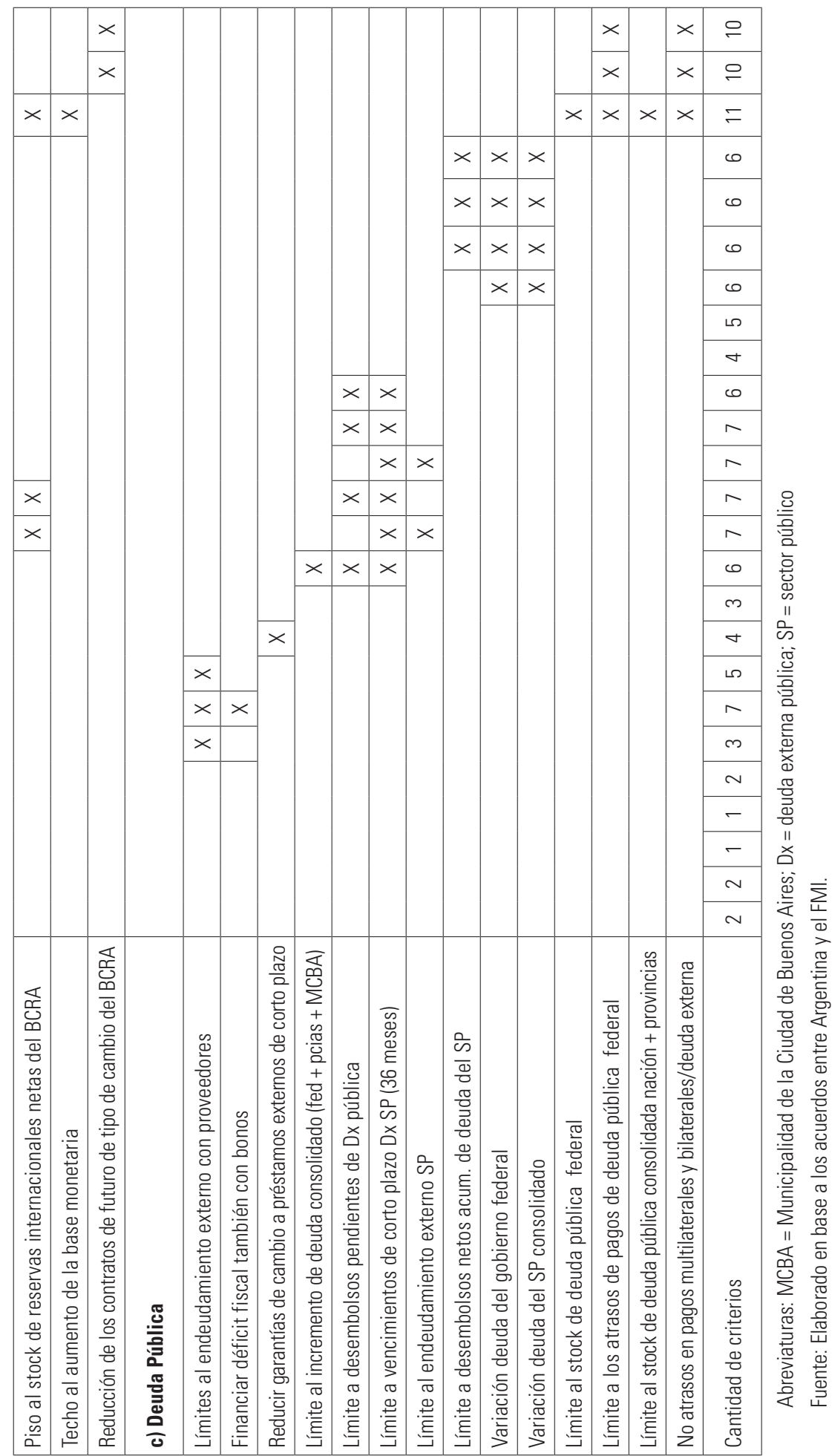




\subsection{Criterios cualitativos de desempeño estructural y reformas estructurales}

Hasta 1977, inclusive, los acuerdos estipulaban muy pocas condicionalidades cualitativas, generalmente, asociadas a los temas de mayor interés para los gobiernos signatarios y para el FMI.

El acuerdo stand by de 1958 exigía estabilizar el mercado cambiario y asegurar financiamiento externo adicional al del FMI, condición imprescindible para el programa económico desarrollista, que procuraba atraer capital extranjero para completar la estructura productiva de base; y el de 1963, exigió crear un registro centralizado de deuda externa pública, que había crecido aceleradamente entre 1959 y 1962, período completo transcurrido bajo programas del FMI, y se hallaba al borde del default.

Los acuerdos de 1967 y 1968 establecieron criterios cualitativos generales vinculados al artículo VIII del Convenio Constitutivo (artículo al que Argentina adhirió en 1968): conservar un mercado cambiario único, no restringir los pagos y transferencias internacionales, permanecer en el sistema multilateral sin discriminación y no celebrar acuerdos bilaterales de pagos. El gobierno militar solicitó ambos acuerdos para atraer préstamos del exterior e inversiones directas - la desnacionalización del tejido empresario fue una de las características del período 196770-, y no giró ni un solo dólar bajo estos dos programas del FMI, que fueron innecesarios ya que no existían dificultades de balance de pagos. Ellos garantizaron la estabilidad cambiaria, a costa de la apreciación del peso, y pocos controles a los movimientos de capitales externos.

El acuerdo stand by de 1976 por primera y única vez estableció como condicionalidad la limitación de los aumentos salariales y el mantenimiento de la libertad de precios. Estas son medidas usuales de los programas del FMI, para disminuir la demanda agregada reduciendo el salario real, pero su 
impopularidad generalmente lleva a disimular su crudeza con eufemismos del lenguaje. Este gobierno dictatorial aplicó el terrorismo de Estado para silenciar toda oposición; disminuir la participación del ingreso asalariado fue uno de sus objetivos, y los acuerdos con el FMI formaron parte de sus instrumentos para lograrlo y exhibirlo sin pudor como baluarte de su poder. En el stand by de 1977, el gobierno se comprometió a mantener la liberación de precios y a reducir las tarifas de importación, medida esta última consistente con los objetivos del FMI, con los mandatos legislativos de los Estados Unidos y los intereses del capital transnacional, y con la ideología ultraliberal del Proceso de Reorganización Nacional, que combinada en 1979 y 1980 con la fuerte sobrevaluación del peso, desató la primera ola de desindustrialización en Argentina, porque los bienes de producción interna no podían competir con los importados, abaratados por un tipo de cambio demasiado bajo e ingresados sin barreras.

Desde la crisis de la deuda externa y hasta 1987 inclusive, los acuerdos stand by entre Argentina y el FMI incluyeron entre nueve y doce condicionalidades cualitativas, que reflejan el rol del organismo como intermediario entre los gobiernos endeudados y los bancos acreedores. Los compromisos de los acuerdos celebrados entre 1983 y 1987 comprendían: a) unificar el mercado cambiario y eliminar controles a la venta de divisas; b) liberar los pagos internacionales y permanecer en el sistema multilateral; c) numerosas cláusulas relacionadas con la gran deuda externa soberana contraída entre 1976 y 1983, básicamente, eliminar atrasos y negociar con los acreedores. Por primera vez, los acuerdos de 1985 y 1987 incluyeron una condición abiertamente favorable al negocio financiero: establecer la tasa de interés regulada real para préstamos en un nivel positivo, mayor que la inflación. El acuerdo stand by de 1984, reanudado en 1985, obligaba también a asegurar financiamiento externo adicional al del FMI. El plan de ajuste de junio de 1985, lanzado junto al reinicio del acuerdo de 1984, y negociado 
previamente con el FMI, prohibía al Banco Central financiar al Tesoro, y obligaba a cubrir el déficit fiscal en el mercado externo. El enfoque monetario del balance de pagos justifica teóricamente esta política, pero no parece saludable para un país sobreendeudado como la Argentina de entonces, adoptar este mecanismo, que aumentaría aun más la deuda externa, como efectivamente ocurrió. El FMI, los bancos acreedores -la mayoría de ellos estadounidenses-, y los sectores domésticos ultrafinanciarizados que crecieron al calor de la dictadura ejercieron una presión brutal sobre el gobierno argentino para condicionar la política económica en el gobierno radical. El sistema democrático todavía era frágil. En 1985, simultáneo al lanzamiento del Plan Austral y a la renegociación del stand by de 1984, se realizó el juicio oral y público de las tres juntas militares de la dictadura que gobernó la Argentina entre 1976 y $1983,{ }^{23}$ y no se descartaba un nuevo golpe castrense.

Atender la elevada deuda externa argentina obligaba a generar saldos comerciales importantes. Pero todos los acuerdos entre Argentina y el FMI entre 1983 y 1989 establecieron condiciones cualitativas - de cumplimiento obligatorio y capaces de provocar la suspensión de los desembolsos- para elevar las importaciones, y también algunas para desalentar las exportaciones no tradicionales. La debilidad de los países endeudados fue aprovechada para obligarlos a abrir sus mercados: el Congreso norteamericano aprobó en 1983 una ley que instruía al director estadounidense para lograr que los países firmantes de acuerdos con el FMI eliminaran las restricciones al comercio y a las inversiones extranjeras, y que la aprobación de los acuerdos y la autorización de los desembolsos tuvieran en cuenta los progresos alcanzados en esta materia. ${ }^{24}$ Esto explica

\footnotetext{
23 El juicio a las Juntas se realizó entre el 22 de abril y el 9 de diciembre de 1985, y concluyó con penas que iban desde los ocho años de prisión hasta la cadena perpetua y la inhabilitación permanente. El Plan Austral fue lanzado en junio de 1985, simultáneo al juicio.

24 Título 22 US Code, ley 286 inc. gg.
} 
la inclusión de la apertura comercial entre las condicionalidades obligatorias de los acuerdos del FMI, a pesar de que ella deteriora el balance de pagos de los países signatarios y contribuye a su desindustrialización y empobrecimiento.

El acuerdo de 1992 dispuso las condiciones cualitativas de privatizar el sistema de seguridad social, eliminar los impuesto a las transacciones financieras y a las ganancias, eliminar las contribuciones patronales a la seguridad social -estas dos últimos medidas no se concretaron-; y generalizar el impuesto al valor agregado, además de eliminar los atrasos en pagos externos. La privatización del Banco Nación constituyó una base de comparación estructural, condición de exigibilidad blanda. Entre 1995 y 2001, los acuerdos de Argentina con el FMI no explicitaron condiciones estructurales. Estas retornaron en el acuerdo de 2003, dirigidas a asegurar el superávit fiscal primario para servir la deuda soberana, y a liberar los pagos internacionales, restringidos desde el default.

Las 8 condicionalidades estructurales del stand by de junio de 2018 se refirieron a la intervención del BCRA en el mercado cambiario; a la gestión de la deuda, como establecer un comité coordinador de gestión de deuda entre los ministerios de hacienda, finanzas y el BCRA, para coordinar semanalmente la esterilización de los ingresos de divisas por deudas y los planes de emisión. También el gobierno se comprometió a presentar al congreso la ley de presupuesto que incluyera los objetivos del programa acordado con el FMI, la ley de reforma del BCRA, limitar las contrapartes del BCRA para la venta de LEBAC, operaciones de mercado abierto y repos a bancos nacionales, recapitalizar el BCRA y diseñar un plan de mejoras del cumplimiento tributario.

Un punto controvertido del acuerdo se refiere al Fondo de Garantía de Sustentabilidad (FGS), conformado con la nacionalización del sistema previsional en 2008. El punto más caliente de este fondo es que posee acciones de grandes empresas. Mientras que la idea original de su creación consistía en aumentar el 
valor del FGS a través de los rendimientos de sus inversiones, el memorándum técnico estipuló que el FGS se trataría como ingresos para compensar parcialmente el gasto futuro en pensiones, es decir que se utilizaría para pagar las pensiones, por lo tanto se iría reduciendo, lo que debilita la sustentabilidad del sistema previsional tal como funciona actualmente.

En el stand by ampliado en octubre de 2018 se explicitaron dos medidas previas a la aprobación, acordadas entre el gobierno y el FMI. La primera, presentar al Congreso el presupuesto 2019 con déficit primario nulo, detalle de la política fiscal, y la anulación del artículo 27 de la ley 11672, referido al registro presupuestario y contable de las obras públicas nacionales. La segunda medida previa consistió en presentar al Congreso una ley para aumentar la alícuota y ampliar la base imponible del impuesto a los ingresos personales.

Las 10 condicionalidades estructurales en la ampliación del stand by en octubre incluyeron las 8 del acuerdo de junio más otras 2, que involucraban la aprobación en el Congreso del presupuesto 2019 con déficit primario nulo, y también legislación de ingresos que sustenta el plan fiscal de 2019.

\section{Argentina: resultados de los programas del FMI en la economía y los derechos humanos}

Es difícil evaluar los resultados de los programas de ajuste acordados con el FMI, porque hay otros factores que influyen en la economía durante su vigencia, pero aún no se han desarrollado técnicas satisfactorias para aislar sus efectos. Uno de los métodos de evaluación más difundidos es comparar la situación de las variables macroeconómicas al principio y al final de los programas, y ese es el que aquí se ha tomado, aplicado a las tres principales variables objetivo de la política macroeconómica: el crecimiento, la inflación y el empleo. Estas variables, a su vez, por su influencia en las condiciones de vida de la población, pueden tomarse como indicadores indirectos, 
o al menos como condiciones, del ejercicio de los derechos económicos y sociales. ${ }^{25}$ Ellos son los derechos a la alimentación, a la vivienda adecuada, a la educación, a la salud, a la seguridad social, a la participación en la vida cultural, al agua y saneamiento, y al trabajo. ${ }^{26}$ Se debe recordar que Argentina no sólo ratificó el Pacto de Derechos Económicos, Sociales y Culturales sino también su Protocolo Optativo.

Más arriba se ha visto que los programas del FMI, a través de sus condicionalidades, impusieron en Argentina, muchas veces con la aquiescencia de los gobernantes de turno, políticas económicas encuadradas en las concepciones neoclásicas y monetaristas, que no son otra cosa que la justificación del predominio de los intereses hegemónicos, a través del discurso pretendidamente científico de la corriente principal, pero de ninguna manera se desprenden de una teoría general unificada, como requiere una disciplina para alcanzar el status de ciencia. De este modo, en cada programa del FMI implementado en Argentina se reiteran medidas lesivas para los derechos económicos y sociales. El ajuste fiscal que reduce el gasto del Estado en fines sociales y aumenta los impuestos y las tarifas de los servicios públicos, afectando el ingreso disponible y el empleo; la política monetaria ortodoxa, que eleva las tasas de interés, reduce el crédito doméstico, inhibe de aplicar medidas para contrarrestar la recesión, y privilegia las ganancias del

\footnotetext{
25 Para profundizar en la cuestión de la incidencia de las medidas económicas ortodoxas sobre los derechos humanos, ver: Aoife Nolan, Economic and Social Rights after the Global Financial Crisis, (Cambridge University Press, Cambridge, 2014); Margot Salomon, Of Austerity, Human Rights and International Institutions, LSELaw, Society and Economy Working Papers 2/2015; UN Committee on Economic, Social and Cultural Rights, "Public Debt, Austerity Measures and the International Covenant on Economic, Social and Cultural Rights", UN Doc. E/C.12/2016/1, (22 de julio de 2016); UN Committee on the Rights of the Child, "General Comment Núm. 19 on Public Budgeting for the Realisation of Human Rights", UN Doc. CRC/ C/GC/19, 2016.

26 Organización de las Naciones Unidas. Preguntas frecuentes sobres los Derechos Económicos, Sociales y Culturales, 2009. Disponible en: https://www.ohchr.org/Documents/ Issues/ESCR/FA0 \%20on \%20ESCR-sp.pdf
} 
sector financiero; el endeudamiento, que desplaza las asignaciones presupuestarias de recursos para todo fin que no sean los servicios de la deuda; la apertura comercial y financiera, que generan desindustrialización, quiebras y transferencias de corrientes de ingresos a los sectores más favorecidos; las reformas estructurales, con sus privatizaciones y desregulaciones, que elevan las ganancias del capital y precarizan el empleo. En suma, para comenzar a dimensionar los efectos de los programas del FMI se aplica aquí una metodología homogénea que abarca el período que va desde el ingreso de Argentina al organismo, en el año 1956, hasta el año 2019. El año 2020 se excluye de este análisis por su excepcionalidad a causa de la pandemia del coronavirus, con sus efectos contractivos sobre la economía mundial y también la nacional.

Cuadro 4. Argentina. Desempeño macroeconómico bajo acuerdos stand by y de facilidades extendidas con el FMI y sin ellos. Variación del PBI, inflación y desempleo, 1956-2019

\begin{tabular}{|c|c|c|c|c|}
\hline \multirow[t]{2}{*}{ Años } & \multirow{2}{*}{$\begin{array}{c}\text { Cantidad de } \\
\text { meses bajo } \\
\text { acuerdo }^{2}\end{array}$} & \multicolumn{2}{|c|}{$\begin{array}{c}\text { Tasa equivalente anual } \\
\text { de variación entre } \\
\text { puntas }\end{array}$} & \multirow{2}{*}{$\begin{array}{c}\begin{array}{c}\text { Tasa de } \\
\text { desempleo } \\
\text { Abierto }\end{array} \\
\begin{array}{c}\text { Variación } \\
\text { absoluta }\end{array}\end{array}$} \\
\hline & & PBI & Inflación & \\
\hline $1956-58$ & 4 & $4,7 \%$ & $23,2 \%$ & Sin datos \\
\hline 1959-63 & 55 & $0,8 \%$ & $41,3 \%$ & Sin datos \\
\hline 1964-66 & 3 & $7,0 \%$ & $35,7 \%$ & $-1,1$ \\
\hline 1967-68 & 23 & $3,5 \%$ & $25,1 \%$ & $-0,8$ \\
\hline $1969-75$ & 4 & $4,0 \%$ & $54,5 \%$ & $-1,6$ \\
\hline 1976-78 & 29 & $1,0 \%$ & $265,0 \%$ & $-2,4$ \\
\hline 1979-81 & 0 & $1,2 \%$ & $114,8 \%$ & 3,3 \\
\hline $1982-2001$ & 194 & $1,6 \%$ & $398,9 \%$ & 15,3 \\
\hline 2002 & 0 & $-10,9 \%$ & $25,9 \%$ & 3 \\
\hline 2003-2004 & 21 & $8,9 \%$ & $1,2 \%$ & $-5,2$ \\
\hline $2005-2017$ & 0 & $3,3 \%$ & $24,3 \%$ & $-5,1$ \\
\hline
\end{tabular}




\begin{tabular}{|c|c|c|c|c|}
\hline \multirow[t]{2}{*}{ Años } & \multirow{2}{*}{$\begin{array}{l}\text { Cantidad de } \\
\text { meses bajo } \\
\text { acuerdo }^{2}\end{array}$} & \multicolumn{2}{|c|}{$\begin{array}{c}\text { Tasa equivalente anual } \\
\text { de variación entre } \\
\text { puntas }\end{array}$} & \multirow{2}{*}{$\begin{array}{c}\text { Tasa de } \\
\text { desempleo } \\
\text { Abierto } \\
\begin{array}{c}\text { Variación } \\
\text { absoluta }\end{array}\end{array}$} \\
\hline & & PBI & Inflación & \\
\hline 2018-2019 & 19 & $-2,30 \%$ & $46,1 \%$ & 1,4 \\
\hline \multicolumn{5}{|c|}{ Excluye valores extremos de 1989 y 1990} \\
\hline 1982-1988 & 47 & $0,40 \%$ & $286,3 \%$ & 2 \\
\hline $1991-2001$ & 130 & $3,30 \%$ & $3,5 \%$ & 12,7 \\
\hline \multicolumn{5}{|c|}{ Promedio Ponderado } \\
\hline \multicolumn{2}{|c|}{$\begin{array}{l}\text { Períodos con } 4 \text { o menos meses } \\
\text { por año bajo acuerdos }\end{array}$} & $3,8 \%$ & $40,4 \%$ & $-3,5$ \\
\hline \multicolumn{2}{|c|}{$\begin{array}{l}\text { Períodos con } 19 \text { a } 55 \text { meses bajo } \\
\text { acuerdos }\end{array}$} & $1,9 \%$ & $81,2 \%$ & 9,7 \\
\hline
\end{tabular}

Fuente: elaboración propia, con datos de los acuerdos entre Argentina y el FMI, INDEC y BCRA.

Para realizar esta evaluación, el período 1956-2019 fue dividido en subperíodos de acuerdo al tiempo de permanencia bajo programas del FMI, la segunda columna del cuadro 4 muestra la cantidad de meses bajo acuerdos del FMI, para cada lapso. Se calculó la variación del PBI entre los extremos de cada período, y se obtuvo la tasa anual equivalente (tercera columna), para comparar los subperíodos, ya que su duración es muy diferente. Luego se calculó la inflación entre puntas, y también la tasa anual equivalente. La variación absoluta de la tasa de desempleo abierto es la diferencia entre la medición más cercana al mes final del período y la más cercana al mes inicial del mismo período.

En primer lugar, se identificaron tres tipos de subperíodos: los que presentan cuatro meses o menos bajo acuerdos con el FMI (1956-58; 1964-66; 1969-75; 1979-81 y 2005-2017); los que involucran aproximadamente dos a cinco años bajo acuerdos con el FMI (1959-63; 1967-68; 1976-78; 2003-04, ya que el gobierno argentino suspendió el stand by el septiembre de 2004; 2018-2019); y el período de larga duración bajo acuerdos con el 
FMI, que va de 1982 a 2001. En algunos años de este último período (1982, 1984 o 1990) la ausencia de acuerdos con el FMI se debió a demoras por controversias en las negociaciones entre el gobierno argentino y el organismo, o a los tiempos de implementación de las condiciones de dispensa para la aprobación de los acuerdos o su reanudación, en caso de que el FMI hubiera suspendido los desembolsos por incumplimiento de metas.

Para eliminar la distorsión que introducirían los valores extremos, el período de larga permanencia bajo acuerdos con el FMI se dividió en dos: 1982-88 y 1991-2001, excluyendo los años de las dos hiperinflaciones, 1989 y 1990; y también se excluyó del cálculo el atípico año 2002, de continua y ardua negociación con el FMI y una caída del PIB del 10,9 \%. El cuadro 4 muestra los promedios ponderados de las variaciones del producto bruto y la inflación en los tres conjuntos de subperíodos, y la variación del desempleo. En los subperíodos con cuatro meses o menos de acuerdos, el crecimiento del producto bruto promedió el 3,8\% anual, la media ponderada de inflación fue 40,4 \% al año, y el desempleo se redujo en tres de los cinco bloques temporales, aunque se carece de datos para 1956-58. Si este análisis excluyera el lapso 1979-81, en que a pesar de la ausencia de acuerdos con el FMI las políticas económicas se mantuvieron dentro de los lineamientos del organismo, los períodos sin acuerdos con el FMI o con muy pocos meses de vigencia, mostrarían aun mejores resultados.

En los períodos de 21 a 55 meses bajo acuerdos con el FMI, el crecimiento promedió $1,9 \%$ anual, muy inferior al de períodos sin acuerdos, la inflación media fue más elevada: 84 \% anual, y el desempleo disminuyó en tres de los cuatro subperíodos (1967-68; 1976-78 y 2003-04), mientras que no se dispone de estadísticas de desempleo para 1959-63.

En la etapa de permanencia prolongada bajo acuerdos con el FMI, 1982-2001, el crecimiento, la inflación y el desempleo experimentaron su peor comportamiento: el producto bruto varió anualmente al 1,6 \% promedio; la media anual inflacionaria fue de 398,9\%; y el desempleo aumentó 15 puntos porcentuales. 
Si se divide esta etapa en dos períodos, antes y después de las hiperinflaciones de 1989 y 1990, se revela que en el lapso de 1982 a 1988 el crecimiento fue menor $(0,4 \%$ anual) y la inflación promedió 286,3 \% anual, con un aumento del desempleo de 2 puntos porcentuales. En el período posterior a la hiperinflación, 1991-2001, la expansión del producto bruto fue 3,3\% anual promedio, más alta que en el lapso previo, aunque de 1999 a 2001 el PIB cayó continuamente; la inflación, anclada en un tipo de cambio fijo, fue de solo 3,5 \% anual; pero el desempleo creció 13 puntos porcentuales, pasando de $6 \%$ en la segunda medición de 1990 (octubre) a 19 \% en igual medición de 2001, una tasa brutal ligada al alza de la pobreza y la indigencia (ver más adelante). El desempleo de dos dígitos comenzó ya en 1993, y se mantuvo elevado en todo el período de la convertibilidad.

El modelo básico del FMI supone que la variación del producto es endógena, y depende positivamente de la variación del crédito doméstico, de las exportaciones netas y del ingreso de capitales, e inversamente, de la velocidad de circulación monetaria. Como se ha visto en el análisis de las condicionalidades, los acuerdos con el FMI restringen el crédito doméstico y favorecen el ingreso de capitales, de modo que el crecimiento del producto depende de esta última variable. Esta relación entre las variaciones del producto y las entradas y salidas de capitales integra la lógica de los planes de ajuste combinados con acuerdos con el FMI: el ingreso de capitales expande el nivel de actividad, su salida lo reduce, por eso el saldo final de los planes de ajuste es pobre en términos del crecimiento económico. El enfoque monetario del balance de pagos no brinda elementos para predecir el comportamiento del empleo, porque asume la plena ocupación. Bajo este supuesto, la oferta agregada de la producción doméstica es inelástica al nivel general de precios, de modo que la inflación depende de las variaciones de la demanda agregada, a su vez, determinadas por las variaciones de la oferta monetaria, variable que en el modelo del FMI queda sujeta a las variaciones de las reservas internacionales —esto es, a los movimientos de 
capitales - y al multiplicador monetario, que se considera constante. En este esquema, el público destinará los excedentes de liquidez a adquirir bienes y servicios, esta presión de demanda sobre una oferta agregada rígida, aumentará los precios, a menos que las importaciones concurran a ampliar la oferta. Por eso, el FMI recomienda reducir el salario real y el crédito doméstico como medidas antiinflacionarias estabilizadoras del tipo de cambio, y facilitar las importaciones, pero esto solo es factible en tanto ingresen capitales. El modelo del FMI considera también que el multiplicador de las importaciones resta dinamismo al crecimiento del producto bruto, porque disminuye el crecimiento de las reservas internacionales y, por ende, la expansión monetaria. En síntesis: los resultados obtenidos en el análisis aquí realizado sobre el impacto de los programas del FMI sobre el crecimiento son consistentes con los previstos en los modelos del FMI.

Los resultados muestran que los programas del FMI no cumplieron un rol antiinflacionario estructural y sustentable en Argentina. En los períodos de vigencia de acuerdos con el FMI la inflación promedio fue más elevada que en aquellos sin acuerdos, porque las medidas previas al lanzamiento de los planes de ajuste ligados a acuerdos con el FMI siempre incluyen la devaluación de la moneda doméstica y aumentos de impuestos y de tarifas de los servicios públicos, medidas que aceleran la inflación; y la inflación también se eleva hacia el final de los programas, porque la represión de variables clave durante su vigencia - el tipo de cambio y el salario real- provoca la acumulación de desequilibrios que luego de algunos años conducen a la ruptura de los planes en un contexto inflacionario y de crisis cambiaria.

En la etapa de permanencia prolongada bajo acuerdos con el FMI, 1982-2001 los efectos negativos sobre el crecimiento, la inflación y el empleo se agudizaron. En 1982-88 el crecimiento fue nulo y la inflación muy elevada, derivando en los procesos hiperinflacionarios de 1989-90. En 1991-2001 el crecimiento fue errático, desde 1993 la inflación se redujo fuertemente pero desde 1999 sobrevino una deflación con recesión; mientras ya 
desde 1993 el desempleo alcanzó cifras de dos dígitos. El costo social, asimismo, fue muy elevado, como surge del incremento de los indicadores de pobreza, indigencia, inseguridad, abandono prematuro de la escolaridad, y trabajo infantil (Cuadro 5). En la etapa 2018-2019 nuevamente los indicadores sociales empeoraron a consecuencia de las políticas regresivas implementadas, profundizadas a través de las condicionalidades del stand by del FMI, respecto de la distribución del ingreso, la reforma previsional, los aumentos de tarifas acordados a las empresas proveedoras de servicios públicos junto a la reducción de subsidios con ese fin, la laxitud importadora, las tasas de interés reales muy positivas, todos ellos rasgos de una economía enfocada en la valorización financiera y la renta de los recursos naturales, características del modelo neoliberal en Argentina.

Lo que nunca ocurre es la frase remanida que figura en todos los acuerdos del FMI: "sentar las bases para un crecimiento sostenido y robusto".

Cuadro 5. Argentina. Algunos Indicadores Sociales, 1991-2001

\begin{tabular}{|l|l|l|r|r|}
\hline \multicolumn{1}{|c|}{ Indicador } & \multicolumn{1}{|c|}{ Medido como } & $\mathbf{1 9 9 1}$ & $\mathbf{2 0 0 1}$ \\
\hline 1 & $\begin{array}{l}\text { Personas bajo línea de } \\
\text { pobreza, octubre }\end{array}$ & \% sobre total población, GBA & 21,5 & 35,4 \\
\hline 2 & $\begin{array}{l}\text { Personas bajo línea de } \\
\text { indigencia, octubre }\end{array}$ & \% sobre total población, GBA & 3 & 12,2 \\
\hline 3 & Tasa de Desempleo, octubre & \% sobre PEA, GBA & 5,3 & 19 \\
\hline 4 & $\begin{array}{l}\text { Población sin cobertura de } \\
\text { salud }\end{array}$ & \% sobre población total país & 36,4 & 48,1 \\
\hline 5 & Escolarización básica & \% s/población de 5 años y + * & 94 & 93,5 \\
\hline 6 & Polimodal & \% s/población de 15 años y + * & 56,8 & 48,6 \\
\hline 7 & Primario & \% s/población de 5 años y + * & 96,4 & 95,7 \\
\hline 8 & Secundario & \% s/población de 12 años y + * & 60,2 & 59,3 \\
\hline 9 & Población penal (presos), SPF & $\begin{array}{l}\text { sobre población total país por } \\
10.000\end{array}$ & 1,5 & 2,1 \\
\hline
\end{tabular}

Fuente: 1 a 3 Encuesta Permanente de Hogares, INDEC; 4 a 8: Censos de Población y Vivienda 1991 y 2001; 9: Servicio Penitenciario Federal. ANEEP, Bs. As., 2004. * En zonas de vigencia de la Ley de Educación Federal. 
Argentina. Algunos Indicadores Sociales, 2018-2019

\begin{tabular}{|l|l|l|r|r|}
\hline \multicolumn{1}{|c|}{ Indicador } & \multicolumn{1}{|c|}{ Medido como } & $\begin{array}{c}\text { 1er sem } \\
\mathbf{2 0 1 8}\end{array}$ & $\begin{array}{c}\text { 2do sem } \\
\mathbf{2 0 1 9}\end{array}$ \\
\hline 1 & $\begin{array}{l}\text { Personas bajo línea de } \\
\text { pobreza }\end{array}$ & $\begin{array}{l}\text { \% sobre total población, 31 } \\
\text { aglomerados urbanos }\end{array}$ & 27,3 & 35,5 \\
\hline 2 & $\begin{array}{l}\text { Personas bajo línea de } \\
\text { indigencia }\end{array}$ & $\begin{array}{l}\text { \% sobre total población, 31 } \\
\text { aglomerados urbanos }\end{array}$ & 4,9 & 8 \\
\hline 3 & $\begin{array}{l}\text { Remuneración al trabajo } \\
\text { asalariado }\end{array}$ & \% sobre Valor Agregado & $\begin{array}{c}\text { IV Trim } \\
\mathbf{2 0 1 7}\end{array}$ & $\begin{array}{c}\text { IV Trim } \\
\mathbf{2 0 1 9}\end{array}$ \\
\hline 4 & Población penal (presos), SPF & Personas & 2017 & $\mathbf{2 0 1 9}$ \\
\hline
\end{tabular}

Fuente: 1 y 2 Encuesta Permanente de Hogares; 3 INDEC; 4: Procuración Penitenciaria de la Nación.

\section{Conclusiones}

El alto cumplimiento de Argentina de sus acuerdos con el FMI, ya que de 22 acuerdos solo 5 fueron suspendidos por el organismo, permite afirmar que la política económica se encuadró, en buena medida, dentro de los lineamientos recomendados por el organismo. Habida cuenta de los muchos años durante los que el país mantuvo acuerdos stand by o de facilidades extendidas, la influencia de sus condicionalidades en la configuración de la economía argentina es intensa y profunda, lo que lleva a investigar sobre la responsabilidad del organismo en las crisis (económicas y de derechos humanos) de Argentina.

La diversidad de las condicionalidades cualitativas y su correspondencia con la idiosincracia de los distintos gobiernos que recurrieron al FMI, señala que las autoridades nacionales a menudo incluyeron en los acuerdos medidas de su interés, con anuencia del FMI, como un modo de forzar su cumplimiento y de enfrentar la resistencia de la población a las cuestiones de mayor costo político y que provocaban el mayor deterioro de los derechos económicos y sociales, como la salud, la educación, 
los salarios y la estabilidad laboral, las jubilaciones y pensiones, y las transferencias a los hogares, entre otros indicadores. El FMI incorporó en las condicionalidades la defensa de intereses privados, como los de los bancos acreedores de la deuda externa argentina y del sistema financiero global, la privatización de la seguridad social y del Banco Nación; la liquidación del Fondo de Garantía de Sustentabilidad del sistema previsional; y también medidas en cumplimiento de mandatos legislativos del Congreso estadounidense, tales como la exigencia de apertura a las importaciones y a las inversiones extranjeras, y de precarización laboral. Es difícil explicar por qué el FMI suspendería un acuerdo con un país miembro si éste no ampliara sus mercados a las importaciones o a las inversiones directas, o si no adoptara cualquiera de las otras medidas mencionadas que claramente escapan de sus incumbencias relativas a la estabilidad del sistema monetario internacional.

Hasta ahora (abril de 2021), lo que se conoce de la propuesta argentina para renegociar el stand by consiste en reducir el déficit fiscal de a poco, y poner el foco en reequilibrar al sector externo, con la ambición de corregir el problema estructural de Argentina de la escasez de divisas; aumentar las exportaciones con valor agregado, en trabajo coordinado con los ministerios de Desarrollo Productivo y de Relaciones Exteriores, y sustituir algunas importaciones, aunque esta es una materia delicada que frunce el ceño de los organismos de Washington. Desdolarizar las transacciones es otra meta oficial, para fortalecer el mercado de capitales en pesos, con el desarrollo de instrumentos financieros en moneda doméstica y una progresiva pesificación de la deuda pública. También hay otros temas no vinculados con el ajuste, como la agenda verde contra el cambio climático y las cuestiones de género en las que el gobierno ha activado políticas y que hoy son importantes para el FMI. En cuanto a las políticas para "los más vulnerables", a juzgar por la realidad de los programas implementados en Argentina y otros países, como Ecuador —el ejemplo más cercano-, el FMI ayuda más a aumentar su cantidad total que a resolver su situación de vulnerabilidad. 